\section{Letter from the President}

by Tae Hong Park

July 9, 2010

Dear ICMA Members,

It is a great honor to be able to serve as President of the International Computer Music Association. My first encounter with the ICMA was at the 1998 ICMC in Michigan. It was without a doubt a memorable and "ear" opening experience on so many levels, ultimately leading me to regularly attend the annual conferences, organize the "Katrina" ICMC in 2006, and recently serve as the ICMA's Vice President for Conferences from 2008 to 2009 under the leadership of Mara Helmuth. As ICMA's recent President, Mara Helmuth contributed greatly to the continuing development of the ICMA. I am certain that I speak for everyone on the board when I say it was wonderful working with her during those two years. And although she will very much be missed at the board meetings, I am sure we will see her regularly at future ICMCis.

It is with confidence that I can tell you the ICMA board members are working very hard to improve the organization by serving not only its membership but also the computer/electronic/electroacoustic music community at large. At the 2010 board meeting in New York, we decided to make the conference papers freely accessible from the ICMA website. The process leading to the consensus to offer free access to the conference papers was not trivial. In the end, however, the agreement seemed to point towards the important idea that ICMA should actively engage in the promotion of computer music, which includes facilitating access to research results not only by ICMA members but also by anyone interested in our field.

We are currently engaged in a number of activities to promote computer music, including exploiting social networking paradigms such as the ICMA Facebook page, providing ICMC conference organizers with more significant interestfree loans than previously available, and much more. We are also very actively researching the feasibility of creating an archive for computer music works that are presented at the conferences, as well as helping to create a professional and functional ICMC media submission system that can be used by future conference hosts. In short, there is much exciting activity currently at the ICMA, and we hope that you will stay tuned and offer us feedback so that we can better serve you. 
As Mara Helmuth wrote in the Array newsletter in 2008, we are always interested in hearing from potential ICMC conference hosts. If you would like information, have any questions regarding what hosting an ICMC entails, or are considering organizing an ICMC conference please contact the VP for Conferences Meg Schedel and me the most up-to-date email addresses can be found on the ICMA website).

If you have any other questions, suggestions, comments, or concerns regarding the ICMA or the ICMC, please do not hesitate to contact me or the appropriate ICMA directors or officers. We hope to see y'all at the 2011 ICMC in Huddersfield!

Sincerely,

Tae Hong Park

Associate Professor, Composition Program Head, Music Science and Technology Programs

Tulane University Music Department

\section{Letter from the Editor}

Since our last issue, Array has undergone some changes. The first relates to the editorship: as of January 2010, Margaret Schedel has taken on the position of Vice President for Conferences on the ICMA board and will no longer be a co-editor of Array. We thank Meg for her years of service to Array, and also for her leadership with ICMC 2010.

The second change has to do with the format of Array. In the past few years, we have released issues electronically as PDF files. While that will still occur, Array has created a blog to enable a more frequent release of content with an opportunity for member feedback. Please point your browsers and RSS readers to http:// arrayblog.wordpress.com.

If you would be willing to write something for Array, have feedback about this issue or ideas for future issues or blog posts, please send email to array@,computermusic.org. Those interested in writing a review should also include a mailing address and any particular areas of interest, so that I can send you any appropriate materials. CD/ DVD and book reviewers will be able to keep review copies free of charge. If you have materials you would like reviewed, please send to: 